\title{
Use of Water-Soluble Curcumin in TPS/PBAT Packaging Material: Interference on Reactive Extrusion and Oxidative Stability of Chia Oil
}

\author{
Naiara Mücke ${ }^{1}$ - Tamires Barlati Vieira da Silva ${ }^{1}$ - Anielle de Oliveira ${ }^{1} \cdot$ Thaysa Fernandes Moya Moreira $^{1}$. \\ Camila Da Silva Venancio ${ }^{2}$ - Leila Larisa Medeiros Marques ${ }^{2}$ - Patrícia Valderrama ${ }^{1}$ Odinei Hess Gonçalves ${ }^{1,3}$. \\ Rosana Aparecida da Silva-Buzanello ${ }^{4}$. Fabio Yamashita ${ }^{5}$. Marianne Ayumi Shirai ${ }^{6}$. Aziza Kamal Genena ${ }^{4}$. \\ Fernanda Vitória Leimann ${ }^{1,3}$ (1)
}

Received: 19 October 2020 / Accepted: 13 January 2021 / Published online: 29 January 2021

(C) The Author(s), under exclusive licence to Springer Science+Business Media, LLC part of Springer Nature 2021

\begin{abstract}
The reactive extrusion technique is efficient in the incorporation of bioactive compounds for active packaging development. The application of curcumin, a strong antioxidant in its pure, isolated form to obtain active packaging has already been investigated; however, the use of water-soluble curcumin (WSC) in thermoplastic starch/poly(butylene adipate-co-terephthalate) (TPS/PBAT) films has not yet been investigated. It is important to determine how WSC would affect starch esterification reaction during reactive extrusion (REx). The use of WSC at $0.5 \% \mathrm{wt}$ led to an increase in tensile strength, elongation at break, and Young's modulus. A reduction in starch esterification was observed; however, an improvement in TPS/PBAT compatibility was detected by infrared spectroscopy, X-ray diffraction, and scanning electron microscopy images. It is worth noting that WSC addition resulted in an increase in the film's solubility and water vapor permeability, due to the hydrophilic character of the WSC. The films were used to package chia oil, and the oxidative stability data were evaluated by UV-Vis spectroscopy coupled with principal component analysis. The addition of WSC $(0.5 \% \mathrm{wt})$ in the films led to the improvement of the oil oxidative stability, suggesting that using water-soluble curcumin may be a promising alternative to active packaging in the case of reactive extruded films.
\end{abstract}

Keywords Reactive extrusion $\cdot$ Compatibility $\cdot$ Oxidative stability $\cdot$ Principal component analysis

\section{Introduction}

The European Regulation (EC) No. 450/2009 describes active packages as systems that "deliberately incorporate components that would release or absorb substances into or from the packaged food or the environment surrounding the food"
(EC 2009). The most studied active package films so far are scavenging systems (such as oxygen scavengers, moisture scavengers, ethylene absorbers) and releasing systems (e.g., antioxidant releasers, carbon dioxide emitters, and antimicrobial packaging systems) (Yildirim et al. 2018).
Fernanda Vitória Leimann

fernandaleimann@utfpr.edu.br

1 Programa de Pós-Graduação em Tecnologia de Alimentos (PPGTA), Universidade Tecnológica Federal do Paraná, Campus Campo Mourão (UTFPR-CM), via Rosalina Maria Dos Santos, 1233, Campo Mourão, PR CEP 87301-899, Brazil

2 Departamento Acadêmico de Alimentos e Engenharia Química (DAAEQ), Universidade Tecnológica Federal do Paraná, Campus Campo Mourão (UTFPR-CM), via Rosalina Maria Dos Santos, 1233, Campo Mourão, PR CEP 87301-899, Brazil
3 Centro de Investigação de Montanha (CIMO), Instituto Politécnico de Bragança, Campus de Santa Apolónia, 5300-253 Bragança, Portugal

4 Departamento Acadêmico de Alimentos, Universidade Tecnológica Federal do Paraná, Campus Medianeira (UTFPR-MD), Av. Brasil, 4232, Medianeira, PR CEP 85884-000, Brazil

5 Departamento de Ciência e Tecnologia de Alimentos, Universidade Estadual de Londrina (UEL), Rod. Celso Garcia Cid (PR 445), Km 380, P.O. Box: 10,011, Londrina, PR CEP: 86057-970, Brazil

6 Departamento Acadêmico de Alimentos, Universidade Tecnológica Federal do Paraná, Campus Londrina (UTFPR-LD), Avenida dos Pioneiros, 3131, Londrina, PR CEP: 86036-370, Brazil 
The use of biological-based polymers, such as polysaccharides, proteins, and lipids, on packaging material composition (de Campos et al. 2019; Menzel 2020; Toro-Márquez et al. 2018) is a trend in food packaging. Furthermore, a costeffective and eco-friendly alternative may be found with the combination of polymers from natural sources with petroleum-based polymers, as an option to the traditional packaging materials (Jacob et al. 2020). Recent efforts also focus on film characterization, especially when a bioactive substance is also incorporated to the polymeric matrix to obtain smart packaging systems (Kim et al. 2020; De Souza et al. 2020).

Starch is a natural, renewable, biodegradable, versatile, inexpensive, and largely available polymer produced by many plants as a source of stored energy (Dufresne 2014). The amylose to amylopectin ratio is a key parameter that varies for different botanical origins (Della Valle et al. 2007). Transformation to thermoplastic starch (TPS) is carried out by the disruption of starch granules and crystalline melting (Muller et al. 2017; Schwach and Avérous 2004). TPS is a costeffective polymer, but its hydrophilic character does not allow its application in many cases due to sensitivity to moisture and high tendency to biodegradation (Jiménez et al. 2012; Nafchi et al. 2013). Blending TPS with poly(butylene adipate-co-terephthalate) (PBAT) is a viable alternative from the processability point of view to produce biodegradable active packaging (Brandelero et al. 2010; da Silva et al. 2019a; de Campos et al. 2019; Hablot et al. 2013; Nunes et al. 2018; Seligra et al. 2016). Although PBAT is a petroleum-based aliphaticaromatic co-polyester polymer with full biodegradability under composting conditions (Shahlari and Sunggyu 2012), PBAT can also be compared to low-density polyethylene (LDPE) concerning its tensile properties. PBAT is totally free of heavy metals and is permitted for food packaging by the Food and Drug Administration (Zehetmeyer et al. 2016). Due to TPS hydrophilicity and PBAT hydrophobicity, the challenge in their combined use is to overcome the poor interfacial adhesion between them. Organic acids, such as citric acid, have been employed as compatibilizers, since their carboxylic acid groups may react with starch hydroxyl groups, grafting single ester groups in the starch chains, thus increasing the compatibility with PBAT by a process called reactive extrusion (REx) (Garcia et al. 2014; Martins and Santana 2016).

Active packaging materials composed of TPS and PBAT have already been produced with success, using pinhão (Araucaria angustifolia) extract (da Silva et al. 2019b), nisin (Zehetmeyer et al. 2016), oregano essential oil (Cardoso et al. 2017), annatto (Leal et al. 2019), and curcumin (de Campos et al. 2019) as active agents. Curcumin is of particular interest because it is a natural compound extracted from the saffron rhizome (Curcuma longa L.), with a yellow-orange color, that presents remarkable antioxidant activity. Campos and coworkers (2019) concluded that curcumin inhibited citric acid reaction with starch molecules, resulting in a less extended esterification degree, and consequently a decrease in the compatibility between TPS and PBAT. In order to modify the solubility of curcumin, its compatibilization with hydrophilic substances is a good alternative, and commercial products are already available. Water-soluble curcumin presents remarkable technological properties and could be used to obtain active package films to prevent food oxidative degradation.

It is known that edible oils have their quality deteriorated by oxidation, a complex process that involves initiation, propagation, and termination steps. The classical methods used to determine food oxidation are usually time and labor consuming with relatively large amounts of reagents or solvents, leading to toxic wastes. In this sense, spectroscopic techniques followed by multivariate data analysis provide an alternative to the traditional chemical methods (Gonçalves et al. 2020; Wójcicki et al. 2015). Principal component analysis is an unsupervised pattern recognition chemometric tool, i.e., an exploratory data analysis method. This tool is feasible to evaluate datasets with correlated variables, removing correlations by transforming complex responses into a new coordinate system in an orthogonal transformation (Leimann et al. 2019).

Although curcumin-added films were already obtained, the use of water-soluble curcumin remains to be evaluated as a technological approach to obtain active packages. The main objective of the present work was to evaluate the viability of producing an active packaging composed of TPS/PBAT by reactive extrusion added with a commercial water-soluble curcumin. As a proof of concept, the film was used to pack chia oil and evaluate its oxidative stability and color changes.

\section{Materials and Methods}

\section{Materials}

Films were produced with cassava starch $(20.8 \pm 0.6 \% \mathrm{wt} / \mathrm{wt}$ amylose, Indemil, Brazil), poly(butylene adipate-co-terephthalate) (PBAT) (Ecoflex®, BASF, Ludwigshafen, Germany), glycerol (Dinâmica, São Paulo, Brazil), citric acid (Sigma-Aldrich, São Paulo, Brazil), and water-soluble curcumin (WSC, IFC Solutions, Linden, USA). Analyticalgrade anhydrous sodium chloride, magnesium nitrate, and magnesium chloride (Dinâmica, São Paulo, Brazil) were used in the water vapor permeability (WVP) analyses.

\section{Production of the TPS/PBAT Films by Blown Film Extrusion}

Films were produced according to the procedure described by de Campos et al. (2019) with minor modifications. The formulations produced (Table 1) were the control film (NC, no curcumin added), film containing $0.05 \%$ wt WSC (NC1), and film containing $0.5 \%$ wt WSC ( $\mathrm{NC} 2)$. 
Table 1 TPS/PBAT film formulations with or without water-soluble curcumin (WSC)

\begin{tabular}{lccc}
\hline & NC & NC1 & NC2 \\
\hline Starch (g) & 490 & 490 & 490 \\
PBAT (g) & 300 & 300 & 300 \\
Glycerol (g) & 210 & 210 & 210 \\
Citric acid (g) & 0.3 & 0.3 & 0.3 \\
WSC (g) & - & 0.5 & 5 \\
\hline
\end{tabular}

Glycerol, citric acid, and curcumin were first mixed, and then PBAT and starch were added and manually mixed (Fig. 1a). The mixture was processed using a laboratory single-screw extruder (model EL-25, BGM, Brazil) with a screw diameter (D) of $25 \mathrm{~mm}, 5$-hp motor (70 RPM), automatic winder, 4 heating zones, and internal and external blowing systems (diameters 150 and $300 \mathrm{~mm}$ ). The barrel temperature profile was $90 / 120 / 120 / 120{ }^{\circ} \mathrm{C}$ in the feeding zone (zone 1) to the die zone (zone 4). The screw speed was of $35 \mathrm{rpm}$, using a die with six holes of 2-mm diameter. Extruded cylindrical profiles were pelletized (Fig. 1b), and the pellets were extruded to produce films with a barrel temperature profile of $90 / 120 / 125 / 125^{\circ} \mathrm{C}$ in the four zones and $130^{\circ} \mathrm{C}$ in the $50-\mathrm{mm}$ film-blowing die with internal air to form the film "bubble" (Fig. 1c). The screw speed of $35 \mathrm{rpm}$ was maintained in this stage. One batch of each formulation (approximately $10 \mathrm{~m}$ long) was produced, and representative parts of each film were used in the subsequent tests.

\section{Film Characterization}

\section{Color and Apparent Opacity}

The color parameters of the CIELAB color system (L* (lightness), $\mathrm{a}^{*}$ (from green $(-)$ to red $(+)$ ), and $\mathrm{b}^{*}$ (from blue (-) to yellow (+))) were evaluated in each formulation using a MiniScan EZ apparatus (HunterLab, Reston, VA, USA), by collecting 20 randomly chosen points in the film's surface.

The apparent opacity of the films was determined according to the method described by Park and Zhao (2004) using a UV-Vis spectrophotometer (Ocean Optics USB650UV, USA). Samples were cut into rectangles and the thickness determined with a digital micrometer (Pantec, São Paulo, Brazil) with 0.001-mm resolution. After that, the films were inserted into a quartz cuvette (10-mm optical path) and adhered to its inner wall, and, finally, the absorbance at $600 \mathrm{~nm}$ was determined, using an empty cuvette as reference. Analyses were carried out in triplicate, and results were expressed as the ratio between the absorbance and film thickness $(\mathrm{mm})\left(\mathrm{Abs}_{600 \mathrm{~nm}} \mathrm{~mm}^{-1}\right)$.

\section{Moisture, Solubility, and Water Vapor Permeability}

Moisture and solubility analyses were performed according to the methodology described by De Oliveira Pizzoli et al. (2017). Films were cut $(2 \times 2 \mathrm{~cm})$, weighted $\left(\mathrm{m}_{1}, \mathrm{~g}\right)$, and dried in a circulation air oven for $24 \mathrm{~h}$ at $60^{\circ} \mathrm{C}$ and weighted again $\left(\mathrm{m}_{2}, \mathrm{~g}\right)$. Dried samples were immersed in distilled water $(200 \mathrm{~mL})$ using a flask under mild stirring in a shaker at $25^{\circ} \mathrm{C}$ for $24 \mathrm{~h}$. Subsequently, the samples were removed from the flasks and dried in a circulation air oven for $24 \mathrm{~h}$ at $60^{\circ} \mathrm{C}$. The samples were individually weighted $\left(\mathrm{m}_{3}, \mathrm{~g}\right)$, and the moisture percentage and the water solubility for each formulation were determined using Eqs. 1 and 2, respectively. The procedure was done in triplicate.
Fig. 1 a Mixture of film components before cylindrical profile production, $\mathrm{b}$ pelletized cylindrical profiles, and c extruded blown films
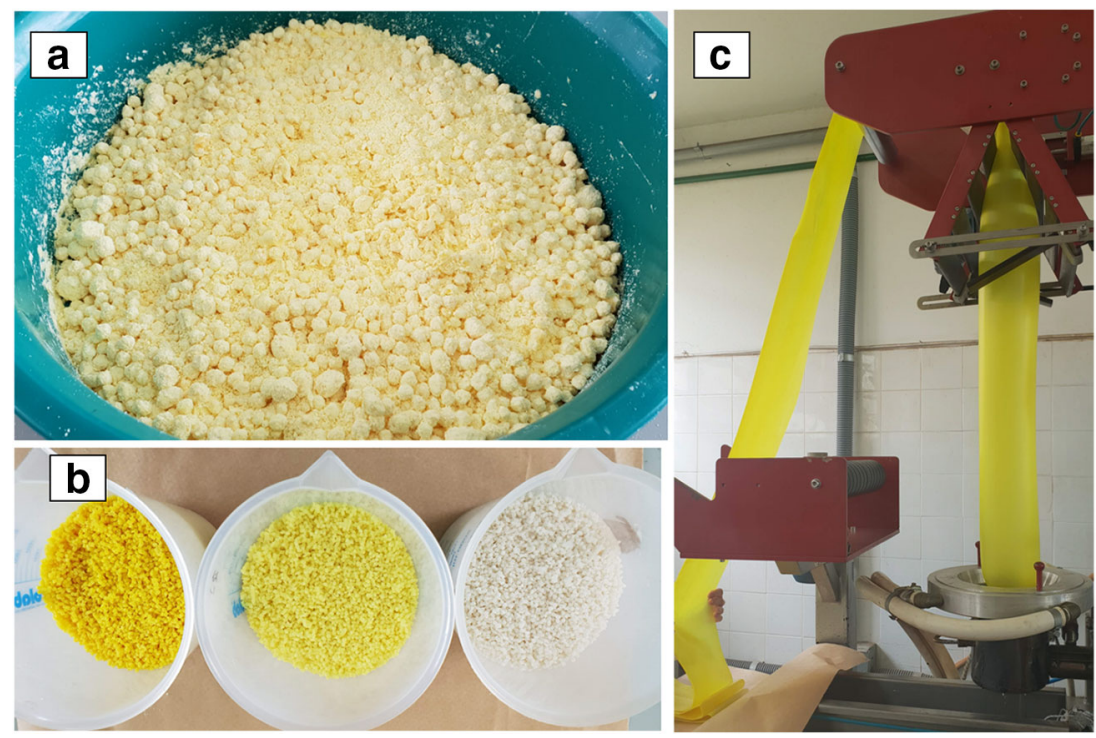
Solubility $(\%)=\frac{m_{2}-m_{3}}{m_{2}} \times 100$

The water vapor permeability (WVP) was determined according to the ASTM E96-00 (1996) procedure using appropriate aluminum diffusion cells under a relative humidity (RH) of $2 \%$ inside the cell and $75 \%$ outside the cell. All tests were carried out in triplicate.

\section{Mechanical, Microstructural, Thermal, and Molecular Characterizations}

A texture analyzer (Stable Micro Systems, model TA.TX2 plus, Surrey, UK) equipped with a 50-kg load cell was used to determine the film's tensile properties. Tensile strength (MPa), Young's modulus (MPa), and elongation at break (\%) were determined based on the ASTM standard D882-02 (ASTM 2002). Six samples of each formulation $(50 \mathrm{~mm}$ length and $20 \mathrm{~mm}$ width to fit the tensile grips) were cut in the longitudinal direction. Tests were carried out using the crosshead speed of $0.8 \mathrm{~mm} / \mathrm{s}$, and the initial distance between the grips equals $30 \mathrm{~mm}$. Samples were conditioned at $23 \pm$ $2{ }^{\circ} \mathrm{C}$ and relative humidity of $53 \pm 2 \%$ for $48 \mathrm{~h}$ before testing.

For the scanning electron microscopy analyses, two samples of each formulation were stored at $25^{\circ} \mathrm{C}$ in a desiccator containing $\mathrm{CaCl}_{2}(\approx 0 \% \mathrm{RH})$ for 3 days and then gold coated (Sputter Coater, BAL-TEC SCD 050, Balzers, Germany). A scanning electron microscope (FEI, Quanta 200, Philips, USA) was used, and the images of fragile fracture $(\times 800 \mathrm{mag}-$ nification) and film's surface $(\times 800$ magnification) were obtained.

The X-ray diffraction patterns were obtained in triplicate for each formulation to qualitatively evaluate the crystallinity of the films using an X-ray diffractometer (Shimadzu, LabX XRD-6000, Kyoto, Japan) at $40 \mathrm{kV}, 53 \mathrm{mV}$, and $\mathrm{Cu} \mathrm{K} \alpha$ radiation $(\lambda=15,433 \hat{\mathrm{A}})$. Samples were analyzed in a range of $2 \theta$ between 2 and $30^{\circ}$ with a scan speed of $5.9^{\circ} / \mathrm{min}$.

For the thermogravimetric analyses (TGA, Shimadzu TGA-50, Kyoto, Japan), film samples (one for each formulation) were previously kept in a desiccator with silica for 3 days. About $10 \mathrm{mg}$ of each sample was weighted into a platinum crucible and heated from 20 to $710^{\circ} \mathrm{C}$ at $10^{\circ} \mathrm{C} / \mathrm{min}$ using an inert atmosphere $\left(\mathrm{N}_{2}, 20 \mathrm{~mL} / \mathrm{min}\right)$. Commercial water-soluble curcumin was analyzed in the same conditions.

Spectra of the blown films were obtained with a Fourier transform infrared spectrometer in attenuated total reflection mode (FTIR-ATR, PerkinElmer Frontier Spectrum 100, Waltham, USA) in the wavenumber range from 2000 to $500 \mathrm{~cm}^{-1}$ at $4 \mathrm{~cm}^{-1}$ resolution and 32 accumulations. Samples (two for each formulation) were conditioned in a desiccator with silica for 3 days before the analyses. Commercial water-soluble curcumin was analyzed in the same conditions.

\section{Oxidative Stability of Packaged Chia Oil}

Chia oil was packed using the produced packaging films (NC, $\mathrm{NC} 1$, and $\mathrm{NC} 2$ ), and its oxidation state was evaluated according to the procedure described by de Campos et al. (2019). The accelerated evaluation method was applied as follows: Eppendorf tubes with the inner part covered by the films ( $\mathrm{NC}, \mathrm{NC1}$, and $\mathrm{NC2}$ ) were filled with $1 \mathrm{~mL}$ of chia oil. In addition, the control sample was prepared by adding $1 \mathrm{~mL}$ of chia oil to a tube without any film coating. The test tubes were placed in an oven (Cienlab, Campinas, SP, Brazil) at $60^{\circ} \mathrm{C}$ for 7 days. Oil absorbance was measured (Ocean Optics model USB-650-UV-VIS, Duiven, The Netherlands) from 360 to $800 \mathrm{~nm}$ at $1-\mathrm{nm}$ resolution and evaluated by principal component analysis (PCA). This procedure was performed in duplicate. The obtained spectra were preprocessed with the baseline correction made by the algorithm available on PLS-Toolbox 5.2 in Matlab software version R2007b (PCA was also applied in the preprocessing step).

\section{Statistical Analysis}

Analysis of variance and the Tukey test at a significance level of $5 \%(p<0.05)$ were used to evaluate the data obtained using the Statistica 7.0 software (Statsoft Inc., Tulsa, OK, USA, 2004).

\section{Results and Discussion}

\section{Physical and Microstructural Characterizations of the Films}

Images of the films produced with the addition of commercial WSC are presented in Fig. 2, as well as SEM images of the film surface and fragile fracture. Color parameters, apparent opacity, moisture, solubility, and WVP are shown in Table 2.

It can be noticed that the color difference between the samples is visually clear (Fig. 2a). Also, SEM images (Fig. 2b) showed that WSC addition to the film formulation decreased the amount of non-gelatinized starch granules on the film's surface. In the fracture images, a layered microstructure was found for both $\mathrm{NC}$ (control film, no curcumin added) and $\mathrm{NC} 1$ (0.05\%wt WSC added) samples. For NC2 sample (0.5\%wt WSC added), a more compact structure may be observed, indicating a higher compatibilization between TPS and PBAT. These results suggest that a better compatibilization was achieved due to the presence of WSC in the concentration used in the $\mathrm{NC} 2$ formulation.

The control film (NC) exhibited a whitish color, typical of TPS/PBAT films obtained by extrusion (da Silva et al. 2019a; Wei et al. 2016). Similar values of lightness were observed for the NC and $\mathrm{NC} 1$ samples $(p>0.05)$, while NC2 exhibited 
Table 2 Color parameters ( $\mathrm{L}^{*}, \mathrm{a}^{*}$, and $\left.\mathrm{b}^{*}\right)$, opacity, moisture, solubility, and water vapor permeability $(W V P)$ determined for TPS/ PBAT films: control formulations $(N C)$, film added to $0.05 \%$ wt of WSC (water-soluble curcumin) ( $\mathrm{NC1}$ ), and film added to $0.5 \%$ wt of WSC (water-soluble curcumin) (NC2)

\begin{tabular}{llll}
\hline & $\mathrm{NC}$ & $\mathrm{NC} 1$ & $\mathrm{NC} 2$ \\
\hline Color parameters & & & \\
$\mathrm{L}^{*}$ & $90.21^{\mathrm{a}} \pm 0.56$ & $90.44^{\mathrm{a}} \pm 1.01$ & $88.99^{\mathrm{b}} \pm 0.98$ \\
$\mathrm{a}^{*}$ & $-2.57^{\mathrm{c}} \pm 0.23$ & $-13.18^{\mathrm{b}} \pm 2.48$ & $-21.03^{\mathrm{a}} \pm 0.30$ \\
$\mathrm{~b}^{*}$ & $2.76^{\mathrm{c}} \pm 0.63$ & $25.61^{\mathrm{b}} \pm 6.37$ & $61.57^{\mathrm{a}} \pm 2.75$ \\
Opacity $\left(\mathrm{Abs}_{600 \mathrm{~nm}} \mathrm{~mm}^{-1}\right)$ & $5.54^{\mathrm{a}} \pm 1.04$ & $5.79^{\mathrm{a}} \pm 0.21$ & $5.49^{\mathrm{a}} \pm 0.93$ \\
Moisture (\%) & $6.99^{\mathrm{a}} \pm 0.34$ & $5.91^{\mathrm{a}} \pm 0.22$ & $6.07^{\mathrm{a}} \pm 0.63$ \\
Solubility (\%) & $20.45^{\mathrm{b}} \pm 0.15$ & $24.14^{\mathrm{a}} \pm 0.28$ & $24.06^{\mathrm{a}} \pm 0.18$ \\
WVP (g (m Pa day $\left.)^{-1}\right)$ & $4.14^{\mathrm{c}} \pm 0.08$ & $4.74^{\mathrm{b}} \pm 0.19$ & $7.20^{\mathrm{a}} \pm 0.07$ \\
$\left(\times 10^{-6}\right)$ & & & \\
& & &
\end{tabular}

Results expressed as mean \pm standard deviation; ${ }^{\text {ab, }, c}$ different letters in the same row indicate significant difference among the treatments by Tukey's test $(p<0.05)$

lower values $(p<0.05)$. There was a decrease of $\mathrm{a}^{*}$ parameter value and an increase in the case of $b^{*}$ parameter when WSC concentration was increased from $0.05 \% \mathrm{wt}(\mathrm{NC} 1)$ to $0.5 \% \mathrm{wt}$ (NC2). This result was expected since curcumin presents yellowish tonality and also is indicative that there was no thermal degradation (Leimann et al. 2019) during the extrusion process. There was no significant difference among the samples in the opacity test $(p>0.05)$. Similar values were reported by de Campos et al. (2019) when comparing TPS/PBAT films added with curcumin in its hydrophobic form. As a side note, in Fig. 2a, it is possible to clearly read the sample names written on a paper below all film samples, meaning they are translucent enough (Ochoa et al. 2017).

WSC addition did not affect the moisture content of the films (Table 2, $p>0.05$ ); however, the water solubility of the WSCadded films ( $\mathrm{NC1}$ and $\mathrm{NC2}$ ) was higher than that of the $\mathrm{NC}$ samples $(p<0.05)$. These films are suitable to be used as low water sensitivity packaging for oily foodstuff, since the presence of a high amount of water could compromise their performance. TPS/PBAT active films were used to pack chia oil (de Campos et al. 2019), lettuce and palm oil (da Silva et al. 2019c), and fresh pasta (Andrade-Molina et al. 2013). Films composed only of PBAT added with oregano essential oil were applied to pack fish fillet (Cardoso et al. 2017), a high water content product, which TPS/PBAT films are not suitable to be applied.

WVP values differed between $\mathrm{NC}$ and $\mathrm{NC} 1$ film formulations when compared to those of NC2 $(p<0.05)$. According to Chen et al. (2009), the number of polar groups available to interact with water molecule may increase vapor permeability.
Fig. 2 (a) Images of the extruded blown films, (b) SEM images of film surface $(\times 800$ magnification) and (c) fragile fracture $(\times 800$ magnification). $\mathrm{NC}$, control (without WSC); NC1, $0.05 \%$ of WSC; NC2, $0.5 \%$ of WSC
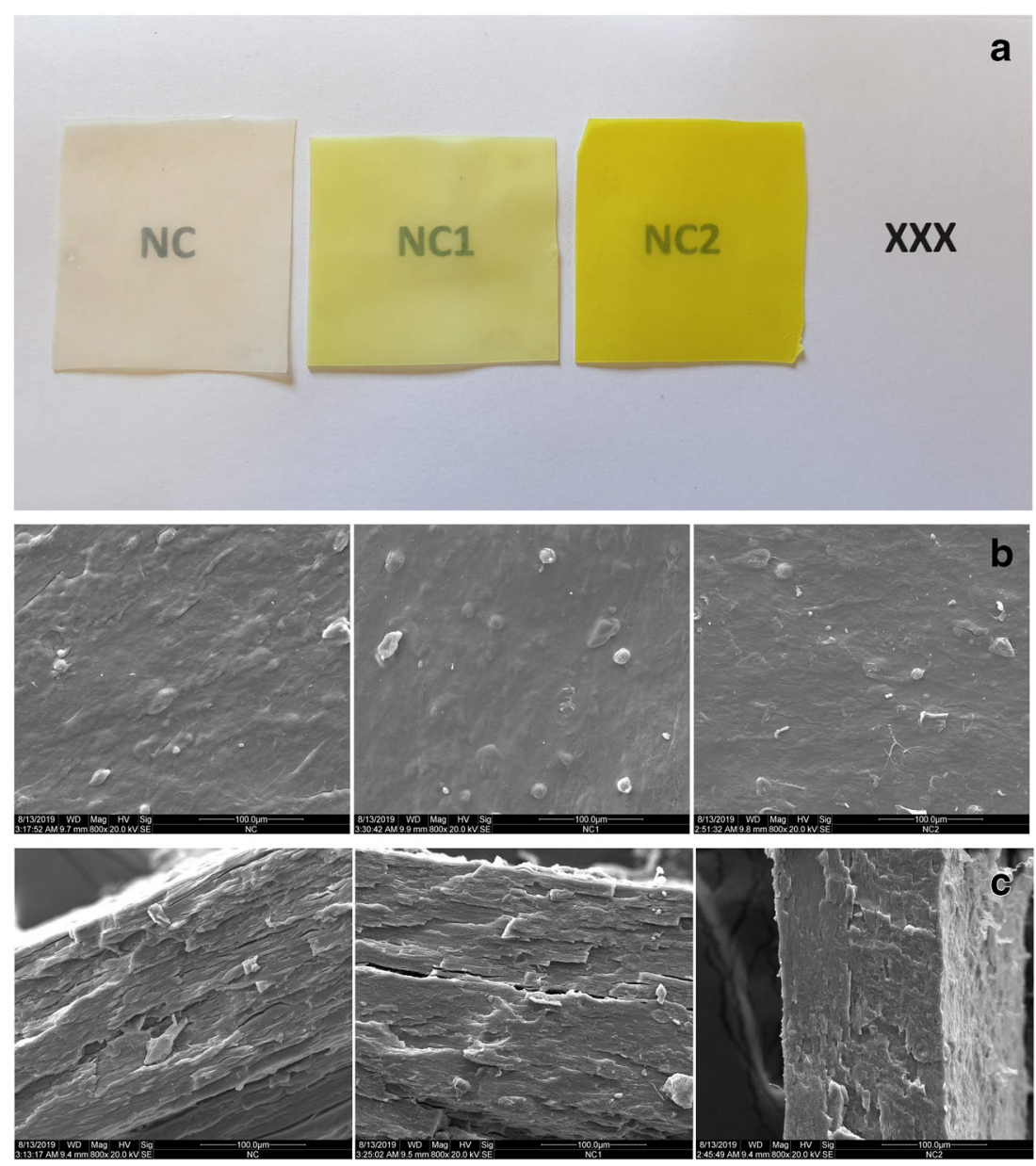
This behavior may be associated with WSC composition, which contains a hydrophilic polymer with polar groups, to encapsulate curcumin and allow it to be soluble in water (Leimann et al. 2019). Since the amount of WSC added in $\mathrm{NC} 2$ formulation was 10-fold higher than that in $\mathrm{NC} 1$, the amount of available polar groups was higher in this case.

\section{Mechanical Properties}

Mechanical properties (tensile strength, Young's modulus, and elongation at break) of the films are presented in Table 3 .

Films exhibited similar tensile strength values $(p>0.05)$ despite the different WSC concentrations used. However, the values of elongation at break differed among all the samples $(p<0.05)$, following the order $\mathrm{NC} 1<\mathrm{NC}<\mathrm{NC} 2$. NC and $\mathrm{NC} 1$ samples exhibited similar values of Young's modulus $(p>0.05)$, suggesting that the addition of $0.5 \%$ wt of WSC (NC2) resulted in more ductile films (Chen et al. 2010). The increase in the elongation at break and also Young's modulus decrease were probably due to an improved TPS-PBAT compatibilization (Lendvai et al. 2017). Furthermore, it is possible that a lower extension of starch esterification/crosslinking by citric acid has occurred in this sample. This finding corroborates with the increase in water solubility (Table 2) since starch with a lower degree of esterification and crosslinking may present greater water solubility (Garcia et al. 2011), as well as a higher elongation at break due to weaker interactions between the chains (Benavides et al. 2012). For $\mathrm{NC} 1$ sample, curcumin could also hinder the action of citric acid in starch (same increase in water solubility as that in $\mathrm{NC2}$ ), but some degree of interaction was held between starch and WSC, since a reduction in elongation at break happened, producing a less elastic material.

de Campos et al. (2019) produced the same TPS/PBAT film using pure, hydrophobic curcumin, allowing the comparison between the films containing WSC. For the formulation containing $0.5 \%$ wt WSC ( $\mathrm{NC} 2)$, increases in tensile strength, elongation at break, and Young's modulus of 1.1-, 9-, and 1.45-fold higher, respectively, were achieved, confirming the increase in compatibility caused by the hydrophilic form of curcumin.

Table 3 Tensile strength (TS), elongation at break (E), and Young's modulus $(Y M)$ of the TPS/PBAT films: control formulation $(N C)$, film added with $0.05 \%$ wt of WSC (water-soluble curcumin, $N C 1$ ), and film added with $0.5 \%$ wt of WSC (water-soluble curcumin, $N C 2$ )

\begin{tabular}{llll}
\hline & $\mathrm{NC}$ & $\mathrm{NC} 1$ & $\mathrm{NC} 2$ \\
\hline $\mathrm{TS}(\mathrm{MPa})$ & $5.83^{\mathrm{a}} \pm 0.32$ & $6.02^{\mathrm{a}} \pm 0.32$ & $5.87^{\mathrm{a}} \pm 0.47$ \\
$\mathrm{E}(\%)$ & $187.76^{\mathrm{b}} \pm 42.49$ & $72.14^{\mathrm{c}} \pm 3.39$ & $258.69^{\mathrm{a}} \pm 37.05$ \\
$\mathrm{YM}(\mathrm{MPa})$ & $37.19^{\mathrm{ab}} \pm 3.54$ & $37.82^{\mathrm{a}} \pm 0.99$ & $33.47^{\mathrm{b}} \pm 2.94$ \\
\hline
\end{tabular}

Results expressed as mean \pm standard deviation; ${ }^{\text {a,b, }}$ different letters in the same row indicate significant difference among the treatments by Tukey's test $(p<0.05)$

\section{X-Ray Diffractometry}

A qualitative evaluation of film crystallinity was carried out with $\mathrm{XRD}$, and the results are presented in Fig. 3a. The obtained patterns demonstrated that the control film sample (NC) presented characteristic crystalline peaks at $2 \theta=17^{\circ}, 20^{\circ}$, and $23^{\circ}$. The peak at $20^{\circ}$ may be related to the crystalline domains of starch of the $\mathrm{V}_{\mathrm{H}}$ type (Olivato et al. 2013). Crystallinity may be induced by extrusion processing and the starch retrogradation. The peaks located at $17^{\circ}$ and $23^{\circ}$ may be related to the PBAT crystallinity and are similar to those observed by Olivato et al. (2013) and Raquez et al. (2006) for TPS/PBAT blend films.

Films incorporated with WSC presented suppression and/or displacement of the peaks located at $17^{\circ}$ and $23^{\circ}$, suggesting a decrease in the film crystallinity when compared to control. It is possible that there was less starch retrogradation in the $\mathrm{NC} 1$ and NC2 samples, resulting in an increase in the amorphous state. This low crystallinity may be associated to the complete melt of starch, favoring film elongation (Olivato et al. 2013). Furthermore, these results suggest a plasticizing effect favored by the water-soluble curcumin, which was much more pronounced for $\mathrm{NC} 2$ treatment. A lower crystallinity degree can also contribute to the compatibilization of the materials (Fig. 2c) and, consequently, resulting in higher elongation at break values (Peng et al. 2017; Sailaja and Chanda 2001).

\section{Fourier Transform Infrared Spectroscopy}

FTIR-ATR spectra of the films and pure WSC are shown in Fig. 3b. WSC presented characteristic absorption bands at 1603 and $1024 \mathrm{~cm}^{-1}$, corresponding to $\mathrm{C}-\mathrm{C}$ aromatic ring (de Almeida et al. 2018a) and C-O groups, respectively (da Silva et al. 2019a). For film samples, characteristic absorption bands of PBAT were observed at 1713 and $1018 \mathrm{~cm}^{-1}$ ( $\mathrm{C}=\mathrm{O}$ group) (Shi et al. 2007). Moreover, PBAT characteristic bands were also observed at $1269 \mathrm{~cm}^{-1}$ and $1102 \mathrm{~cm}^{-1}$ related to symmetric $\mathrm{C}-\mathrm{O}$ stretching vibration, at $1102 \mathrm{~cm}^{-1}$ related to phenylene ring $\mathrm{CH}$-plane bending, and at $727 \mathrm{~cm}^{-1}$ corresponding to the deformation band of $-\mathrm{CH}_{2}-$ of the aromatic ring (de Maria Vaz Conceição et al. 2019).

A decrease in the intensity of the C-O symmetric vibration $\left(1269 \mathrm{~cm}^{-1}\right)$ of the PBAT was observed when the WSC concentration was increased. This behavior may be associated to the interaction between WSC and PBAT, which can also be associated to the higher compatibility between PBAT and TPS (Fig. $2 \mathrm{~b}$ and $\mathrm{c}$ ) and to the ductile behavior of the films containing WSC (Table 3).

The presence of WSC in the films also led to a decrease in the absorption bands located at 1729 and $1713 \mathrm{~cm}^{-1}$. These bands are associated to the esterification between citric acid and starch and/or glycerol and/or PBAT (Garcia et al. 2011), meaning that curcumin may be responsible for hindering the esterification 
Fig. 3 a XRD patterns and $b$ FTIR-ATR spectra obtained for WSC, NC (control film), NC1 (TPCS/PBAT film with $0.05 \%$ wt of WSC), and NC2 (TPCS/PBAT film with $0.5 \%$ wt of WSC)
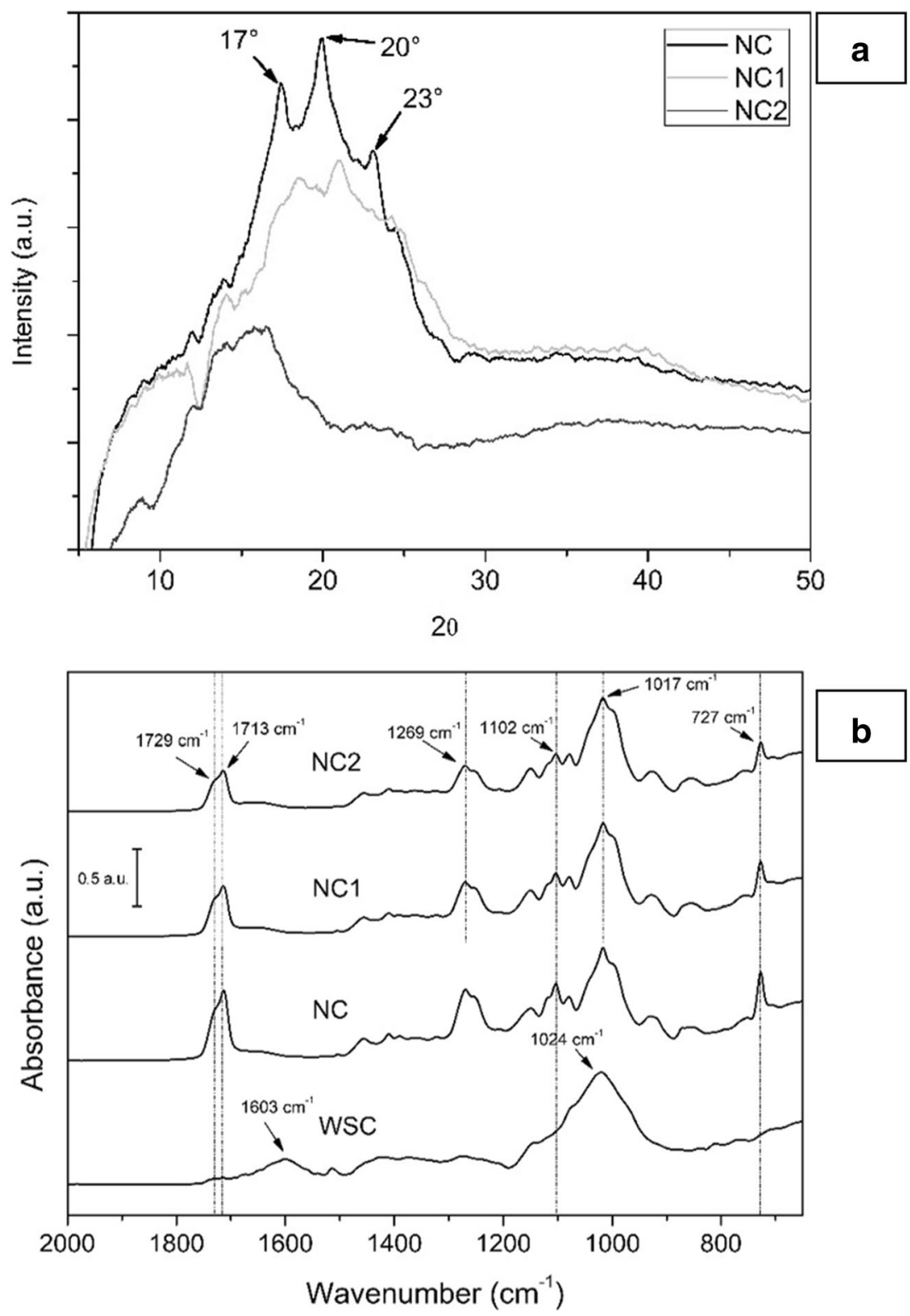

reaction. The same behavior was found by de Campos et al. (2019) when using pure curcumin as an active agent for TPS/ PBAT films. FTIR-ATR results are in accordance with film solubility presented in Table 2 . Despite suppressing starch esterification, WSC showed molecular interaction with PBAT, leading to a compatibilizer and plasticizer effect.

\section{Thermogravimetric Analysis}

TG curves and the respective derivative curves (DTG) of films and WSC are presented in Fig. 4. The onset and maximum temperatures determined for TPS and PBAT degradation, as well as the weight loss determined for each thermal event, are presented in Table 4.
WSC presented thermal events at $68{ }^{\circ} \mathrm{C}, 333{ }^{\circ} \mathrm{C}$, and $489{ }^{\circ} \mathrm{C}$. The first event of weight loss $(8 \%)$ may be related to moisture loss, while the second and third events are related to WSC thermal degradation ( $59 \%$ and $18 \%$, respectively). For NC and NC1 film samples, three thermal events were observed, while for NC2 four events were found. The first event was found for film samples at $95{ }^{\circ} \mathrm{C}$ (NC with $8 \%$ weight loss), $146{ }^{\circ} \mathrm{C}$ ( $\mathrm{NC} 1,9 \%$ weight loss), and $112{ }^{\circ} \mathrm{C}$ (NC2, 10\% weight loss). This initial weight loss is related to sample moisture, as well as glycerol evaporation (de Campos et al. 2019). The second thermal event may be associated with TPS degradation (de Campos et al. 2019; Lendvai et al. 2017) and presented an increase in weight loss in function of WSC amount added to films, as observed in Table 4. The third thermal event, associated with PBAT degradation (de 
Table 4 Degradation temperatures of TPS and PBAT (peak's onset and maximum) and weight loss at degradation TPS and PBAT peaks

\begin{tabular}{|c|c|c|c|c|c|c|}
\hline \multirow[t]{2}{*}{ Formulation } & \multirow[t]{2}{*}{$\mathrm{T}_{\text {TPS }}$ onset $\left({ }^{\circ} \mathrm{C}\right)$} & \multirow[t]{2}{*}{$\mathrm{T}_{\mathrm{TPS}} \max \left({ }^{\circ} \mathrm{C}\right)$} & \multirow[t]{2}{*}{$\mathrm{T}_{\mathrm{PBAT}}$ onset $\left({ }^{\circ} \mathrm{C}\right)$} & \multirow[t]{2}{*}{$\mathrm{T}_{\mathrm{PBAT}} \max \left({ }^{\circ} \mathrm{C}\right)$} & \multicolumn{2}{|c|}{$\begin{array}{l}\text { Mass loss in } \\
\text { degradation (\%) }\end{array}$} \\
\hline & & & & & TPS & PBAT \\
\hline $\mathrm{NC}$ & 280 & 370 & 370 & 491 & 39.1 & 31.4 \\
\hline $\mathrm{NC1}$ & 277 & 369 & 369 & 500 & 41.5 & 31.1 \\
\hline $\mathrm{NC} 2$ & 271 & 368 & 368 & 469 & 42.0 & 27.5 \\
\hline
\end{tabular}

Campos et al. 2019; Lendvai et al. 2017), presented an inverse behavior when compared to TPS weight loss.

The degradation of TPS showed a decrease in the function of WSC concentration, while PBAT-onset temperature presented a small difference between treatments, being the same behavior observed by de Campos et al. 2019). Probably, this result is related to a crystallinity reduction (Lv et al. 2015) due to the WSC presence (Fig. 3a), as well as by the higher thermal degradation stability associated to the crosslinked starch, since in NC sample citric acid effectively esterified starch, possibly producing crosslinked starch. On the other hand, for PBAT, maximum temperature showed an increase

of $9{ }^{\circ} \mathrm{C}(\mathrm{NC} 1)$ when compared to control, possibly related to the interaction observed between PBAT and WSC as observed in the FTIR spectra (Liu et al. 2019). However, there was a decrease of $22^{\circ} \mathrm{C}$ for $\mathrm{NC} 2$ sample when compared to control, which may be due to the plasticizing effect of WSC (Table 3).

\section{Oxidative Stability of Packaged Chia Oil}

The UV-Vis spectra of the chia oil (control before packaging), chia oil packaged in different systems (NC, NC1, and NC2) over time, and the PCA results are shown in Fig. 5.
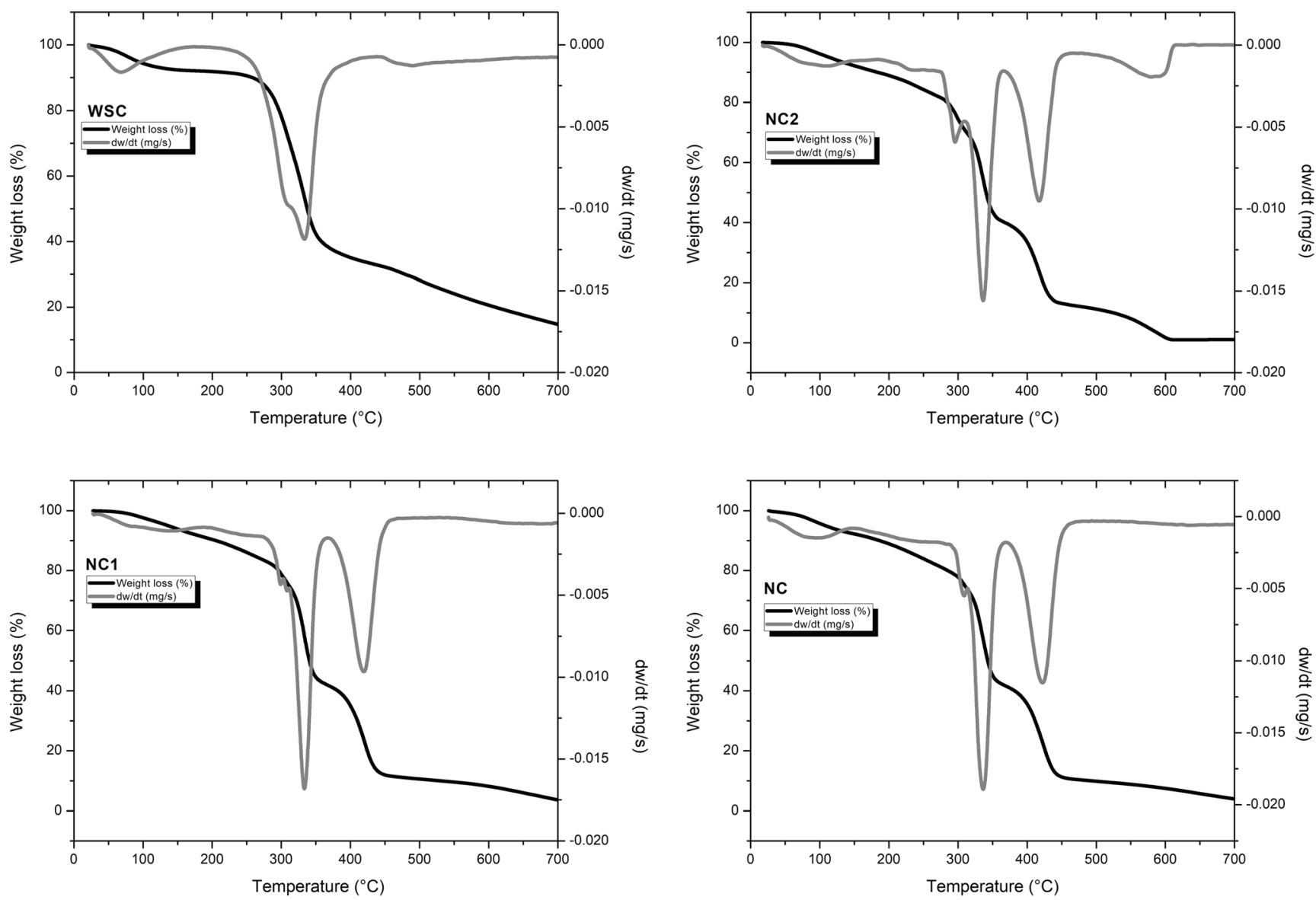

Fig. 4 Thermogravimetric (TG) and derivative (DTG) curves of pure WSC (water-soluble curcumin), NC (control film), NC1 (TPS/PBAT film with $0.05 \%$ wt of WSC), and NC2 (TPS/PBAT film with $0.5 \%$ wt of WSC) 

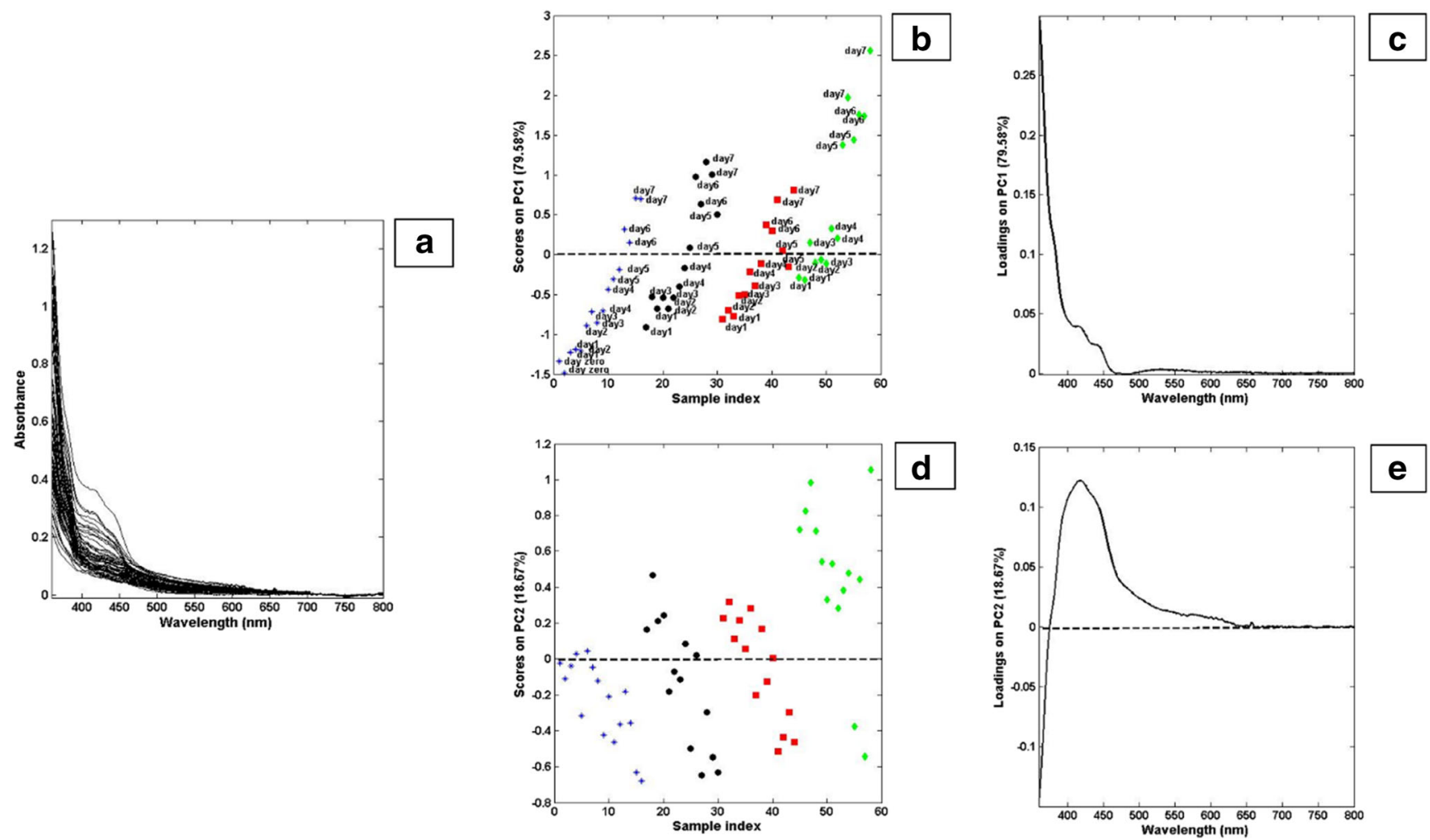

Fig. 5 a UV-Vis spectra, b scores on PC1, c loadings on PC1, d scores on PC2, e loadings on PC2: (*) control samples; (•) chia oil packaged in NC; ( $\bullet$ ) chia oil packaged in $\mathrm{NC} 1 ;(\bullet)$ chia oil packaged in $\mathrm{NC} 2$

PCA was used in order to improve the interpretability of the results, since UV-Vis spectroscopy is known to lack selectivity toward specific chemical groups. The first two PCs were responsible for more than $98 \%$ of the explained variance of the data. The chia oil (control) and chia oil in different packaging had similar behaviors over time, considering the two PCs. Taking into account that heating is a form to start the oxidation process (de Almeida et al. 2018b; Venturini et al. 2018), it can be observed that chia oil (control) with PC1 scores on the negative side (Fig. 5b) presented an increase in the oxidation products over time. It can be noted that $\mathrm{NC}$ and $\mathrm{NC1}$ packages are more effective in retarding the oxidation at the beginning of the process, meaning that $\mathrm{PC} 1$ brought relevant information to explain chia oil behavior during the storage time and the package effects. The behavior of packaged chia oil oxidation process on the first day was similar to the control samples on day 2 under heating. Moreover, packages $\mathrm{NC}$ and $\mathrm{NC} 1$ present similar behaviors to prevent the start of the oxidation process. On the other hand, for NC2 package, the behavior of chia oil oxidation process on day 1 was similar to that of the control samples on day 5 under heating. These results suggest that package $\mathrm{NC} 2$ promoted more stability to the oil when compared to $\mathrm{NC1}$ and $\mathrm{NC}$. The loadings on PC1 (Fig. 5c) are in agreement with those of a previous work when the oxidation product spectrum was recovered (Gonçalves et al. 2014). de Campos et al. (2019) also packaged chia oil into TPS/PBAT blends containing hydrophobic curcumin. The oxidative stability results were evaluated by MCR-ALS (multivariate curve resolution with alternating least squares), were an increase on the concentration of oxidation products within the storage time was verified. The authors concluded that chia oil was protected by the film added with $0.5 \%$ wt of curcumin, presenting a lower concentration of the oxidation products throughout the experiment. The same behavior was observed at the present work, being $0.5 \%$ wt of WSC to optimal concentration to chia oil preservation.

Regarding PC2 scores (Fig. 5d), it was observed that chia oil (control) was concentrated on the negative side, while oil sample packaged in $\mathrm{NC} 2$ was concentrated in the positive part. Oil samples packaged in $\mathrm{NC}$ and $\mathrm{NC1}$ presented an intermediate position between the negative and positive sides. Concerning to the loadings on PC1 (Fig. 5e), a pattern of scores on PC2 was observed, due to the curcumin absorption behavior, and suggests that they can be assigned to the curcumin yellow color. This loading plot resembles the pure curcumin spectra on different solvents found by Subhan et al. (2013) and Van Nong et al. (2016) and demonstrates curcumin has migrated to the oil during the test. 


\section{Conclusion}

WSC was successfully incorporated into blown extrusion TPS/PBAT blend films. Results indicated that the presence of WSC hindered the action of citric acid as a compatibilizer, increasing the water solubility and water vapor permeability of the films. SEM images showed a more compact structure without phase separation for this sample when WSC was added to the films. Film color was clearly affected by WSC addition, but opacity remained unaltered. A ductile behavior was detected when the highest concentration of WSC was used, which may be related to the film's microstructure and interactions between WSC and PBAT. Furthermore, WSC addition resulted in a less crystalline film, as well as a slightly lower thermal stability. UV-Vis spectroscopy coupled to chemometric analyses showed that the film containing $0.5 \%$ wt WSC was able to protect chia oil from oxidation, suggesting that it is a promising approach to produce high-performance food package systems.

Acknowledgements The authors thank the "Central Analítica Multiusuário da UTFPR Campo Mourão" (CAMulti-CM) for the analyses. Fernanda V. Leimann (process 039/2019) and Patrícia Valderrama (process 033/2019) thank Fundação Araucária (CP 15/2017- Programa de Bolsas de Produtividade em Pesquisa e Desenvolvimento Tecnológico).

Funding This study was financed in part by the Coordenação de Aperfeiçoamento de Pessoal de Nível Superior - Brasil (CAPES) Finance Code 001.

\section{References}

de Almeida, M., de Rocha, B. A., Francisco, C. R. L., Miranda, C. G., Santos, P. D. D. F., De Araújo, P. H. H., et al. (2018a). Evaluation of the in vivo acute antiinflammatory response of curcumin-loaded nanoparticles. Food \& Function, 9(1), 440-449. https://doi.org/10. 1039/c7fo01616f.

Andrade-Molina, T. P. D. C., Shirai, M. A., Victória Eiras Grossmann, M., \& Yamashita, F. (2013). Active biodegradable packaging for fresh pasta. LWT - Food Science and Technology, 54(1), 25-29. https://doi.org/10.1016/j.lwt.2013.05.011.

ASTM, (1996) E96-00: standard test methods for water vapor transmission of materials.

ASTM. (2002). American Society for Testing and Materials. D 882-02: Standard test method for tensile properties of thin plastic sheeting. ASTM International, 14, 1-10.

Benavides, S., Villalobos-Carvajal, R., \& Reyes, J. E. (2012). Physical, mechanical and antibacterial properties of alginate film: Effect of the crosslinking degree and oregano essential oil concentration. Journal of Food Engineering, 110(2), 232-239. https://doi.org/10.1016/j. jfoodeng.2011.05.023.

Brandelero, R. P. H., Yamashita, F., \& Grossmann, M. V. E. (2010). The effect of surfactant Tween 80 on the hydrophilicity, water vapor permeation, and the mechanical properties of cassava starch and poly(butylene adipate-co-terephthalate) (PBAT) blend films. Carbohydrate Polymers, 82(4), 1102-1109. https://doi.org/10. 1016/j.carbpol.2010.06.034. de Campos, S. S., de Oliveira, A., Moreira, T. F. M., da Silva, T. B. V., da Silva, M. V., Pinto, J. A., Bilck, A. P., Gonçalves, O. H., Fernandes, I. P., Barreiro, M. F., Yamashita, F., Valderrama, P., Shirai, M. A., \& Leimann, F. V. (2019). TPCS/PBAT blown extruded films added with curcumin as a technological approach for active packaging materials. Food Packaging and Shelf Life, 22, 1-9. https://doi.org/ 10.1016/j.fpsl.2019.100424.

Cardoso, L. G., Pereira Santos, J. C., Camilloto, G. P., Miranda, A. L., Druzian, J. I., \& Guimarães, A. G. (2017). Development of active films poly (butylene adipate co-terephthalate) - PBAT incorporated with oregano essential oil and application in fish fillet preservation. Industrial Crops and Products, 108(January), 388-397. https://doi. org/10.1016/j.indcrop.2017.06.058.

Chen, B., Shen, C., Chen, S., \& Chen, A. F. (2010). Ductile PLA modified with methacryloyloxyalkyl isocyanate improves mechanical properties. Polymer, 51(21), 4667-4672. https://doi.org/10.1016/j. polymer.2010.08.028.

Chen, C., Kuo, W., \& Lai, L. (2009). Effect of surfactants on water barrier and physical properties of tapioca starch/decolorized hsian-tsao leaf gum films. Food Hydrocolloids, 23(3), 714-721. https://doi.org/10. 1016/j.foodhyd.2008.06.006.

da Silva, J. B. A., Santana, J. S., Lucas, A. D. A., Passador, F. R., da Silva Costa, L. A., Pereira, F. V., \& Druzian, J. I. (2019a). PBAT/TPSnanowhiskers blends preparation and application as food packaging. Journal of Applied Polymer Science, 47699(26), 1-10. https://doi. org/10.1002/app.47699.

da Silva, T. B. V., Moreira, T. F. M., de Oliveira, A., Bilck, A. P., Gonçalves, O. H., Ferreira, I. C. F. R., et al. (2019b). Araucaria angustifolia (Bertol.) Kuntze extract as a source of phenolic compounds in TPS/PBAT active films. Food \& Function, 10(12), 76977706. https://doi.org/10.1039/C9FO01315F.

de Almeida, M. M. C., Francisco, C. R. L., de Oliveira, A., de Campos, S. S., Bilck, A. P., Fuchs, R. H. B., et al. (2018b). Textural, color, hygroscopic, lipid oxidation, and sensory properties of cookies containing free and microencapsulated chia oil. Food and Bioprocess Technology, 1-14. https://doi.org/10.1007/s11947-018-2057-x.

De Oliveira Pizzoli, A. P., Yamashita, F., Gonçalves, O. H., Shirai, M. A., \& Leimann, F. V. (2017). The effect of gelatin amount on the properties of PLA/TPS/gelatin extruded sheets. Polimeros, 27(1), 27-34. https://doi.org/10.1590/0104-1428.2181.

Della Valle, G., Vergnes, B., \& Lourdin, D. (2007). Viscous properties of thermoplastic starches from different botanical origin. International Polymer Processing, 22(5), 471-479. https://doi.org/10.3139/217. 2057.

Dufresne, A. (2014). Crystalline starch based nanoparticles. Current Opinion in Colloid and Interface Science, 19(5), 397-408. https:// doi.org/10.1016/j.cocis.2014.06.001.

EC. Commission Regulation (European Commission-EC), (2009) $\mathrm{N}^{\circ}$ $450 / 2009$ of 29 May 2009 on active and intelligent materials and articles intended to come into contact with food. https://eur-lex. europa.eu/legal-content/PT/TXT/HTML/?uri=CELEX: 32009R0450\&from $=\mathrm{EN}$

de Maria Vaz Conceição, E., Filho, A. L. M. M., da Silva Roque, L., de Moura do Amaral Pires, F., Webster, T. J., Marciano, F. R., \& Lobo, A. O. (2019). In vivo evaluation of the genotoxic effects of poly nanohydroxyapatite scaffolds for bone regeneration. Materials, 12(1130), 1-16.

Garcia, P. S., Eiras Grossmann, M. V., Yamashita, F., Mali, S., Dall'Antonia, L. H., \& Barreto, W. J. (2011). Citric acid as multifunctional agent in blowing films of starch/PBAT. Quimica Nova, 34(9), 1507-1510. https://doi.org/10.1590/S010040422011000900005.

Garcia, P. S., Grossmann, M. V. E., Shirai, M. A., Lazaretti, M. M., Yamashita, F., Muller, C. M. O., \& Mali, S. (2014). Improving action of citric acid as compatibiliser in starch/polyester blown 
films. Industrial Crops and Products, 52, 305-312. https://doi.org/ 10.1016/j.indcrop.2013.11.001.

Gonçalves, R. P., Março, P. H., \& Valderrama, P. (2014). Thermal edible oil evaluation by UV-Vis spectroscopy and chemometrics. Food Chemistry, 163, 83-86. https://doi.org/10.1016/j.foodchem.2014. 04.109.

Gonçalves, T. R., Rosa, L. N., Torquato, A. S., da Silva, L. F. O., Março, P. H., Gomes, S. T. M., Matsushita, M., \& Valderrama, P. (2020). Assessment of Brazilian monovarietal olive oil in two different package systems by using data fusion and chemometrics. Food Analytical Methods, 13(1), 86-96. https://doi.org/10.1007/s12161019-01511-w.

Hablot, E., Dewasthale, S., Zhao, Y., Zhiguan, Y., Shi, X., Graiver, D., \& Narayan, R. (2013). Reactive extrusion of glycerylated starch and starch-polyester graft copolymers. European Polymer Journal, 49(4), 873-881. https://doi.org/10.1016/j.eurpolymj.2012.12.005.

Jacob, J., Thomas, S., Loganathan, S., \& Valapa, R. B. (2020). Antioxidant incorporated biopolymer composites for active packaging. In Zhang, Y. (Ed.), Processing and development of polysaccharide-based biopolymers for packaging applications (pp. 239-260). Elsevier Inc. https://doi.org/10.1016/b978-0-12-818795$1.00010-1$.

Jiménez, A., Fabra, M. J., Talens, P., \& Chiralt, A. (2012). Edible and biodegradable starch films: A review. Food and Bioprocess Technology, 5(6), 2058-2076. https://doi.org/10.1007/s11947-0120835-4.

Kim, I., Viswanathan, K., Kasi, G., Thanakkasaranee, S., Sadeghi, K., \& Seo, J. (2020). ZnO nanostructures in active antibacterial food packaging: preparation methods, antimicrobial mechanisms, safety issues, future prospects, and challenges. Food Reviews International, 00(00), 1-29. https://doi.org/10.1080/87559129. 2020.1737709 .

Leal, I. L., da Silva Rosa, Y. C., da Silva Penha, J., Cruz Correia, P. R., da Silva Melo, P., Guimarães, D. H., et al. (2019). Development and application starch films: PBAT with additives for evaluating the shelf life of Tommy Atkins mango in the fresh-cut state. Journal of Applied Polymer Science, 136(43), 1-19. https://doi.org/10.1002/ app.48150.

Leimann, V. F., Gonçalves, O. H., Sorita, G. D., Rezende, S., Bona, E., Fernandes, I. P. M., Ferreira, I. C. F. R., \& Barreiro, M. F. (2019). Heat and $\mathrm{pH}$ stable curcumin-based hydrophilic colorants obtained by the solid dispersion technology assisted by spray-drying. Chemical Engineering Science, 205, 248-258. https://doi.org/10. 1016/j.ces.2019.04.044.

Lendvai, L., Apostolov, A., \& Karger-Kocsis, J. (2017). Characterization of layered silicate-reinforced blends of thermoplastic starch (TPS) and poly(butylene adipate-co-terephthalate). Carbohydrate Polymers, 173, 566-572. https://doi.org/10.1016/j.carbpol.2017. 05.100 .

Liu, W., Liu, S., Wang, Z., Dai, B., Liu, J., Chen, Y., Zeng, G., He, Y., Liu, Y., \& Liu, R. (2019). Preparation and characterization of reinforced starch-based composites with compatibilizer by simple extrusion. Carbohydrate Polymers, 223(January), 115122. https://doi. org/10.1016/j.carbpol.2019.115122.

Lv, S., Gu, J., Cao, J., Tan, H., \& Zhang, Y. (2015). Effect of annealing on the thermal properties of poly (lactic acid)/starch blends. International Journal of Biological Macromolecules, 74, 297-303. https://doi.org/10.1016/j.ijbiomac.2014.12.022.

Martins, A. B., \& Santana, R. M. C. (2016). Effect of carboxylic acids as compatibilizer agent on mechanical properties of thermoplastic starch and polypropylene blends. Carbohydrate Polymers, 135, 79-85. https://doi.org/10.1016/j.carbpol.2015.08.074.

Menzel, C. (2020). Improvement of starch films for food packaging through a three-principle approach: antioxidants, cross-linking and reinforcement. Carbohydrate Polymers, 250, 116828. https://doi. org/10.1016/j.carbpol.2020.116828.
Muller, J., González-Martínez, C., \& Chiralt, A. (2017). Combination of poly(lactic) acid and starch for biodegradable food packaging. Materials, 10(8), 1-22. https://doi.org/10.3390/ma10080952.

Nafchi, A. M., Moradpour, M., Saeidi, M., \& Alias, A. K. (2013). Thermoplastic starches: properties, challenges, and prospects. Starch/Staerke, 65(1-2), 61-72. https://doi.org/10.1002/star. 201200201.

Nunes, M. A. B. S., Marinho, V. A. D., Falcão, G. A. M., Canedo, E. L., Bardi, M. A. G., \& Carvalho, L. H. (2018). Rheological, mechanical and morphological properties of poly (butylene adipate-co-terephthalate)/thermoplastic starch blends and its biocomposite with babassu mesocarp. Polymer Testing, 70, 281-288. https://doi.org/ 10.1016/j.polymertesting.2018.07.009.

Ochoa, T. A., Almendárez, B. E. G., Reyes, A. A., Pastrana, D. M. R., López, G. F. G., Belloso, O. M., \& González, C. R. (2017). Design and characterization of corn starch edible films including beeswax and natural antimicrobials. Food and Bioprocess Technology, 10(1), 103-114. https://doi.org/10.1007/s11947-016-1800-4.

Olivato, J. B., Nobrega, M. M., Müller, C. M. O., Shirai, M. A., Yamashita, F., \& Grossmann, M. V. E. (2013). Mixture design applied for the study of the tartaric acid effect on starch/polyester films. Carbohydrate Polymers, 92(2), 1705-1710. https://doi.org/ 10.1016/j.carbpol.2012.11.024.

Park, S. I., \& Zhao, Y. (2004). Incorporation of a high concentration of mineral or vitamin into chitosan-based films. Journal of Agricultural and Food Chemistry, 52(7), 1933-1939. https://doi. org/10.1021/jf034612p.

Peng, N., Gu, L., Li, J., Chang, C., Li, X., \& Su, Y. (2017). Films based on egg white protein and succinylated casein cross-linked with transglutaminase. Food and Bioprocess Technology, 10(8), 14221430. https://doi.org/10.1007/s11947-017-1901-8.

Raquez, J.-M., Nabar, Y., Narayan, R., \& Dubois, P. (2006). Finite strain 3D thermoviscoelastic constitutive model. Polymer Engineering \& Science, 48(9), 1747-1754. https://doi.org/10.1002/pen.

Sailaja, R. R. N., \& Chanda, M. (2001). Use of maleic anhydride-grafted polyethylene as compatibilizer for HDPE-tapioca starch blends: Effects on mechanical properties. Journal of Applied Polymer Science, 80(6), 863-872. https://doi.org/10.1002/10974628(20010509)80:6<863::AID-APP1164>3.0.CO;2-R.

Schwach, E., \& Avérous, L. (2004). Starch-based biodegradable blends: Morphology and interface properties. Polymer International, 53(12), 2115-2124. https://doi.org/10.1002/pi.1636.

Seligra, P. G., Moura, L. E., Famá, L., Druzian, J. I., \& Goyanes, S. (2016). Influence of incorporation of starch nanoparticles in PBAT/TPS composite films. Polymer International, 65(8), 938945. https://doi.org/10.1002/pi.5127.

Shahlari, M., \& Sunggyu, L. (2012). Mechanical and morphological properties of poly(butylene adipate-co-terephthalate) and poly(lactic acid) blended with organically modified silicate layers. Polymer Engineering and Science, 52(7), 13-17. https://doi.org/10.1002/ pen.

Shi, R., Zhang, Z., Liu, Q., Han, Y., Zhang, L., Chen, D., \& Tian, W. (2007). Characterization of citric acid/glycerol co-plasticized thermoplastic starch prepared by melt blending. Carbohydrate Polymers, 69(4), 748-755. https://doi.org/10.1016/j.carbpol.2007. 02.010 .

da Silva, M. N., de Matos Fonseca, J., Feldhaus, H. K., Soares, L. S., Valencia, G. A., de Campos Maduro, C. E., et al. (2019c). Physical and morphological properties of hydroxypropyl methylcellulose films with curcumin polymorphs. Food Hydrocolloids, 97(March), 105217. https://doi.org/10.1016/j.foodhyd.2019.105217.

De Souza, K. C., Correa, L. G., Barlati, T., Fernandes, T., Moreira, M., De Oliveira, A., et al. (2020). Soy protein isolate films incorporated with pinhão (Araucaria angustifolia (Bertol.) Kuntze) extract for potential use as edible oil active packaging. Food and Bioprocess Technology, 13(6), 998-1008. 
Subhan, M. A., Alam, K., Rahaman, M. S., Rahman, M. A., \& Awal, R. (2013). Synthesis and characterization of metal complexes containing curcumin $\left(\mathrm{C}_{21} \mathrm{H}_{20} \mathrm{O}_{6}\right)$ and study of their anti-microbial activities and DNA-binding properties. Journal of Scientific Research, 6(1), 97-109. https://doi.org/10.3329/jsr.v6i1.15381.

Toro-Márquez, L. A., Merino, D., \& Gutiérrez, T. J. (2018). Bionanocomposite films prepared from corn starch with and without nanopackaged Jamaica (Hibiscus sabdariffa) flower extract. Food and Bioprocess Technology, 11(11), 1955-1973. https://doi.org/ 10.1007/s11947-018-2160-z.

Van Nong, H., Hung, L. X., Thang, P. N., Chinh, V. D., Van Vu, L., Dung, P. T., et al. (2016). Fabrication and vibration characterization of curcumin extracted from turmeric (Curcuma longa) rhizomes of the northern Vietnam. Springer Plus, 5(1), 1147. https://doi.org/10. 1186/s40064-016-2812-2.

Venturini, L. H., Moreira, T. F. M., da Silva, T. B. V., de Almeida, M. M. C., Francisco, C. R. L., de Oliveira, A., de Campos, S. S., Bilck, A. P., de Souza Leone, R., Tanamati, A. A. C., Gonçalves, O. H., \& Leimann, F. V. (2018). Partial substitution of margarine by microencapsulated chia seeds oil in the formulation of cookies. Food and Bioprocess Technology, 2014(1), 77-87. https://doi.org/10.1007/ s11947-018-2188-0.
Wei, D., Wang, H., Ziaee, Z., Chibante, F., Zheg, A., \& Xiao, H. (2016). Non-leaching antimicrobial biodegradable PBAT films through a facile and novel approach. Materials Science and Engineering $C$, 58, 986-991. https://doi.org/10.1016/j.msec.2015.09.023.

Wójcicki, K., Khmelinskii, I., Sikorski, M., \& Sikorska, E. (2015). Near and mid infrared spectroscopy and multivariate data analysis in studies of oxidation of edible oils. Food Chemistry, 187, 416-423. https://doi.org/10.1016/j.foodchem.2015.04.046.

Yildirim, S., Röcker, B., Pettersen, M. K., Nilsen-Nygaard, J., Ayhan, Z., Rutkaite, R., Radusin, T., Suminska, P., Marcos, B., \& Coma, V. (2018). Active packaging applications for food. Comprehensive Reviews in Food Science and Food Safety, 17(1), 165-199. https:// doi.org/10.1111/1541-4337.12322.

Zehetmeyer, G., Meira, S. M. M., Scheibel, J. M., De Oliveira, R. V. B., Brandelli, A., \& Soares, R. M. D. (2016). Influence of melt processing on biodegradable nisin-PBAT films intended for active food packaging applications. Journal of Applied Polymer Science, 133(13), 1-10. https://doi.org/10.1002/app.43212.

Publisher's Note Springer Nature remains neutral with regard to jurisdictional claims in published maps and institutional affiliations. 